\title{
Thrombopoietic activity in preterm newborns and infants
}

\author{
L SIROTA, H BESSLER, Z WEISSMAN, F DULITZKY, AND M DJALDETTI
}

Neonatology Unit, Hematologic Laboratory, and Department of Medicine 'B', Hasharon Hospital, PetahTiqva, Tel Aviv University Medical School, Israel

SUMmARY Platelet count and thrombopoietic activity were investigated in preterm infants at birth and during their first four months of life. Thrombopoiesis stimulating factor activity in cord serum was significantly lower than that of adults and of the respective mothers. No difference was noted between thrombopoietic activity in cord serum in the various gestational ages studiedthat is, 24 through 39 weeks. Preterm infants followed during their first four months of life showed a mean platelet count significantly higher than that observed in term infants at the respective age. Furthermore, thrombocytosis was found in premature thriving infants at the age of 1 and 2 months. It is suggested that this thrombocytosis is responsible for the low thrombopoietic activity observed in these infants during their first four months of life.

Platelet production is regulated by thrombopoiesis stimulating factor or thrombopoietin..$^{1-3}$ This humoral factor acts on megakaryocyte progenitors inducing differentiation, ${ }^{4}$ maturation, ${ }^{5}$ proliferation, ${ }^{6}$ and increased platelet production.

In the adult the production of thrombopoiesis stimulating factor and platelets depends on a negative feedback mechanism. ${ }^{7}$ In term newborns the regulation of platelet production seems to be different from that in the adult. In our previous study a significantly lower thrombopoietic activity was found in the sera of newborns in comparison with that of adults. ${ }^{8}$ In addition, the activity in cord serum was significantly lower than that of the respective mothers. In a follow up study during the first four months of life it was found that thrombopoietic activity gradually increased, reaching in the fourth month activities similar to those of adults. Concomitantly with the rise in thrombopoietic activity in the serum, an increased platelet count was observed. ${ }^{8}$

The aim of the present study was to determine platelet count and thrombopoietic activity in preterm newborns and infants for a better understanding of the regulation mechanism of platelet production during fetal and the first months of life and to compare the results with those obtained in term infants.

\section{Material and methods}

Subjects. Twenty seven preterm infants aged 24 to
35 weeks' gestation were examined. The gestational age was calculated from the first day of the mother's menstrual bleeding preceding pregnancy and was confirmed by clinical examination (Dubowitz scoring). The mean birth weight of the infants ranged from 500 to $3000 \mathrm{~g}$ (mean $1747 \mathrm{~g}$ ).

Four premature babies born at a gestational age of 24-25 weeks and weighing 500-700 g died a few hours after birth. Babies who underwent exchange transfusion were excluded from the study. The follow up study included infants at the ages of 2 weeks (22 infants), 1 month (18), 2 months (13), and 4 months (12). During the follow up period the infants received either breast milk or infant milk formula. In addition to vitamins $A, D$, and $C$ folic acid $1 \mathrm{mg} /$ day was given. From the age of 2 months elemental iron $2 \mathrm{mg} / \mathrm{kg} /$ day was administered. Vitamin $\mathrm{E}$ was not given routinely.

Thrombopoietic activity was investigated in the preterm babies' mothers' blood soon after delivery. Fifteen healthy volunteers (seven women and eight men) aged 20 to 40 years served as controls.

Methods. Blood was withdrawn from the umbilical cord of 27 preterm newborns after ligation of the cord from the newborn side of the placenta. Concomitantly, venous blood was obtained from the respective mothers. The venous blood was withdrawn from the infants at the age of 2 weeks and 1 , 2 , and 4 months. Cord and venous blood samples (of preterm newborns and infants, their respective mothers, and control adults) were centrifuged, and 
the serum was stored at $-20^{\circ}$ until analysed. The serum samples were tested for thrombopoietic activity within two weeks after withdrawal, a period in which the activity has been shown to be stable at storage. ${ }^{9}$

Haemoglobin concentration and packed cell volume were detected with a Coulter counter Model -S (Coulter Electronic Ltd, England). Platelets were counted with a light microscope using a Neubauer chamber.

Thrombopoiesis stimulating factor assay. Thrombopoiesis stimulating factor was measured by the method of Penington. ${ }^{9}$ This assay is based on the ability of thrombopoietic activity in the serum to stimulate platelet production as measured by increased concentrations of ${ }^{75} \mathrm{Se}$-selenomethionine incorporated into circulating platelets of a recipient animal. Eight to 10 week old female BDF mice weighing between 20 and $25 \mathrm{~g}$ were used. The mice were injected subcutaneously twice daily with $0.5 \mathrm{ml}$ of serum for two days. Each mouse was injected with a total volume of $2 \mathrm{ml}$ of serum sample. Adult serum was injected into five mice, cord serum into four, and serum of every preterm newborn into one or two. Five mice injected with $0.9 \%$ sodium chloride solution served as controls for each experiment. On the third day the mice were injected intravenously with $2 \mu \mathrm{C}$ of ${ }^{75}$ selenomethionine ( ${ }^{75}$ Se-Met, Amersham, England). The isotope incorporation into platelets was calculated 24 hours later by a previously described method. ${ }^{10}$

Thrombopoietic activity was investigated in different experiments and the results were adjusted for interassay variation.

Statistical analysis was carried out by the Student's $t$ test. The study was approved by the local ethical committee, and informed parental consent was obtained.

\section{Results}

Both newborns and adults showed a significantly higher serum thrombopoietic activity compared with saline controls $(p<0 \cdot 0005$, Fig. 1). No difference was found between thrombopoietic values in the serum of male or female adults. Thrombopoietic activity in the preterm newborns' umbilical cord serum was significantly lower in comparison with that of their respective mothers $(p<0.0005$, Fig. 1).

The results of thrombopoietic activity in the preterm cord blood was divided into three groups according to the newborns' gestational age: 24-30 weeks, 31-33 weeks, and 34-36 weeks. No difference was noted in thrombopoietic activity between these three groups (Table 1).

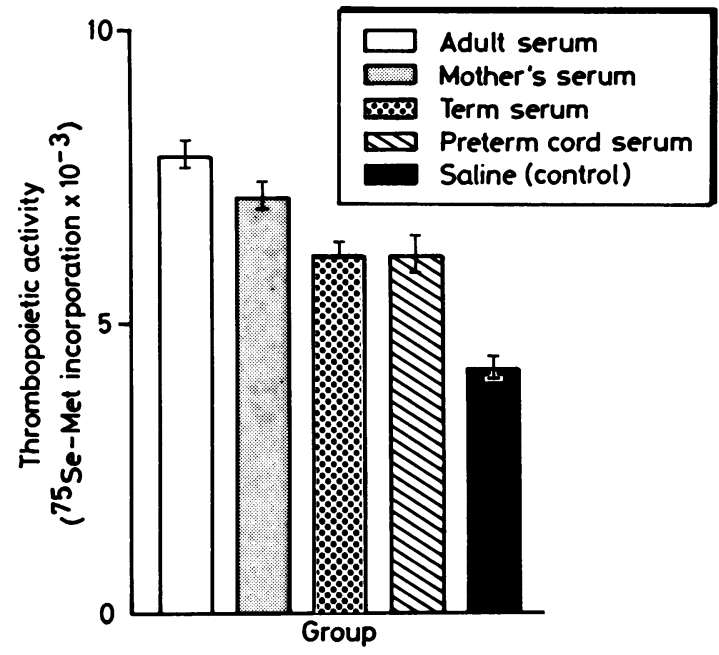

Fig. 1 Thrombopoietic activity in the serum of adults, mothers, and term and preterm infants. Mice injected with saline served as control. Thrombopoietic activity in the controls was significantly lower than in the other four groups. Each column represents mean (SEM) (bars).

Table 1 Platelet count and thrombopoiesis stimulating factor activity in adults, and cord blood of term, and preterm newborns of various gestational ages

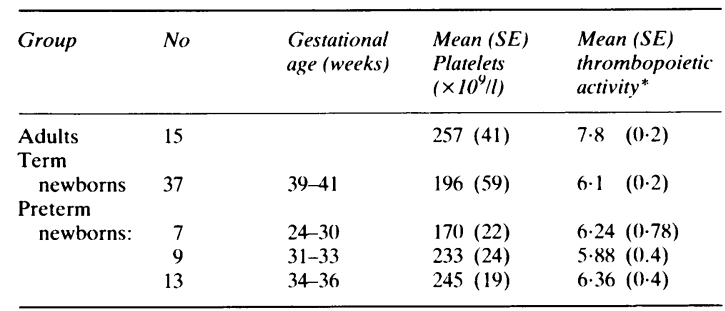

${ }^{*} \%{ }^{75} \mathrm{Se}-$ Met incorporation into platelets $\times 10^{3}$.

Thrombopoietic activity in the maternal serum was significantly lower compared with that of adults $(p<0 \cdot 01$, Fig. 1). Follow up at the ages of 2 weeks and 1,2, and 4 months showed a significantly lower thrombopoietic activity compared with that of adults $(\mathrm{p}<0.0005, \mathrm{p}<0.0005, \mathrm{p}<0.005$, and $\mathrm{p}<0.005$, respectively) (Table 2 ). Thrombopoietic activity in premature infants was significantly lower at 2 months $(p<0.01)$ and lower at 4 months compared with that observed in term infants at the respective age (Fig. 2).

No difference was detected between preterm cord blood and adults' platelet counts (Table 3 ). Preterm infants who were 2 weeks and 1,2, and 4 months old showed significantly raised platelet counts compared with those of adults: $425000 \pm 33000$, 
Table 2 Haematological data and thrombopoiesis stimulating factor activity in preterm newborns and infants.

Values are mean (SE)

\begin{tabular}{|c|c|c|c|c|c|}
\hline Specification & $n=$ & $\begin{array}{l}\text { Haemoglobin } \\
(\mathrm{g} \%)\end{array}$ & $\begin{array}{l}\text { Reticulocytes } \\
(\%)\end{array}$ & $\begin{array}{l}\text { Platelets } \\
\left(\times 10^{9} / l\right)\end{array}$ & $\begin{array}{l}\text { Thrombopoietic } \\
\text { activity* }\end{array}$ \\
\hline $\begin{array}{l}\text { Cord blood } \\
2 \text { week old }\end{array}$ & 27 & $15 \cdot 7(0.56)$ & $2.12(0.32)$ & $221(15)$ & $6.08(0.29)$ \\
\hline newborns & 22 & $13.6(0.53)$ & $0.8(0.09)$ & $425(33)$ & $5.59(0.4)$ \\
\hline $\begin{array}{l}\text { Infants: } \\
1 \text { month old } \\
2 \text { month old } \\
4 \text { month old }\end{array}$ & $\begin{array}{l}18 \\
13 \\
12\end{array}$ & $\begin{aligned} 9.8 & (0.6) \\
9.3 & (0.37) \\
10.8 & (0.2)\end{aligned}$ & $\begin{array}{l}1.05(0.17) \\
1.84(0.27) \\
0.99(0.11)\end{array}$ & $\begin{array}{l}461(42) \\
466(44) \\
357(44)\end{array}$ & $\begin{array}{l}6.20(0.25) \\
5.58(0.25) \\
6.50(0.38)\end{array}$ \\
\hline
\end{tabular}

*\% ${ }^{75}$ Se-Met incorporation into platelets $\times 10^{9}$.

Table 3 Clinical and haematological data in preterm newborns and adults. Values are mean (SE)

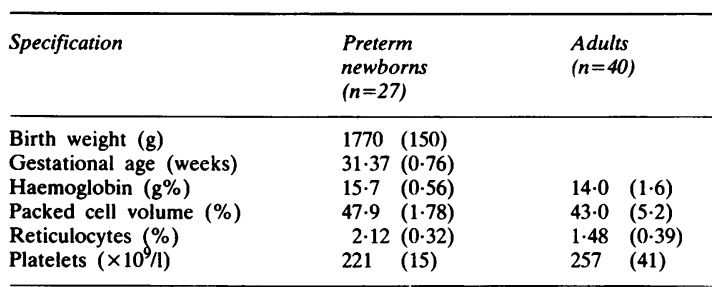

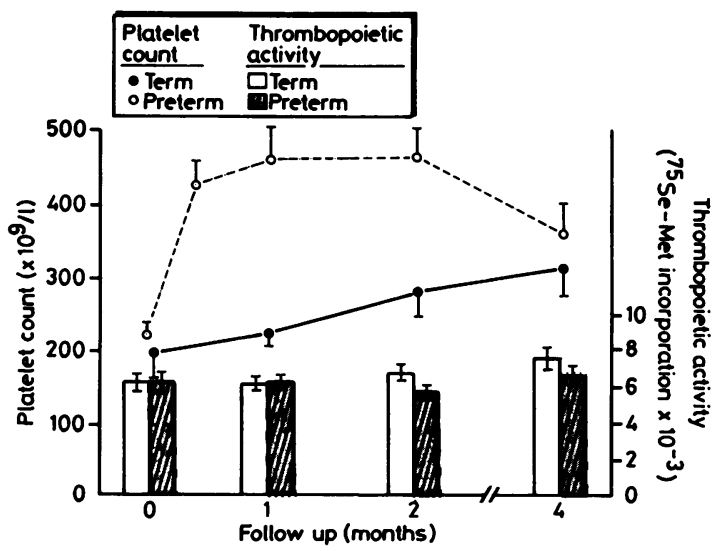

Fig. 2 Platelet count and thrombopoietic activity in preterm and term infants during their first four months of life. Each column and experimental point represents mean (SEM) (bars).

$461000 \pm 42000, \quad 466000 \pm 44000$ and $357000 \pm$ $44000 / \mathrm{mm}^{3}$, respectively $(\mathrm{p}<0.0005, \mathrm{p}<0.0005$, $p<0.0005$, and $p<0.0125$ ). At the age of 1 and 2 months preterm infants' platelet counts were significantly higher than those of term infants at the respective ages $(p<0.0005$ and $p<0.005$, Fig. 2). At the age of 4 months the preterm infants' platelet count decreased to a level similar to that observed in term infants at the same chronological age (Fig. 2).

\section{Discussion}

The present work shows a significantly lower thrombopoietic activity in the serum of preterms' cord blood and premature infants during the first four months of life compared with that of adults. In addition, preterm infants showed a mean platelet count significantly higher than that observed in term infants at the respective age. As a negative feed back mechanism exists between platelet count and thrombopoietic production, it might be suggested that the thrombocytosis observed in the preterm infants during the first four months of life is responsible for the suppression of thrombopoietic production. The finding that at the age of 4 months a mild rise in thrombopoietic activity occurred concomitantly with a decrease in platelet count supports this suggestion.

The thrombocytosis found in preterm thriving infants in our study accords with a recent report by Lundström, ${ }^{11}$ who observed high platelet counts in premature infants during a follow up from 2 weeks to 6 months. Furthermore, Aballi et al reported considerably higher values of platelets at 2 weeks and 1 month in a large series of 300 premature infants. ${ }^{12}$ It is therefore suggested that thrombocytosis is a physiological phenomenon in preterm infants during the first few months of life.

Thrombocytosis was reported in infants and children connected with various diseases,${ }^{13}$ of which iron and vitamin $\mathrm{E}$ deficiency are likely to be the most common causes in preterm infants. In the previous study of Lundström no difference was observed between iron supplemented and non-supplemented infants. ${ }^{11}$ Furthermore, all premature infants were treated with vitamin $E$ routinely. In our study thrombocytosis was first noted at the age of 2 weeks, which is known to be too early to suggest iron deficiency or vitamin $\mathrm{E}$ deficiency, or both. Moreover, no clinical signs of vitamin E deficiency could be observed in the preterm infants included in our study.

The mechanism that regulates platelet count in 
the preterm infant is unknown. It is suggested that the thrombocytosis noted in preterm infants during the first months of life might result from the sizable expansion of blood volume that accompanies rapid weight gain in these infants, a condition that has aptly been described as 'bleeding into the circulation' ${ }^{14}$ Such a condition mimics haemorrhage and may cause iron deficiency anaemia, both of which are conditions that are known to result in thrombocytosis.

The significantly lower thrombopoietic activity in premature cord serum compared with that of the respective mother suggests that thrombopoiesis stimulating factor does not cross the placenta and that the regulation of its production is under the control of the fetus itself. Furthermore, as no difference in the activity was observed between preterm and term cord serum at the various gestational ages, starting as early as 24 weeks, it is conceivable to conclude that the embryo manifests a low thrombopoietic activity independently of its gestational age. Both findings are supported by our previous study, ${ }^{8}$ which has shown significantly lower thrombopoietic activity in term cord blood compared with that of the respective mother.

\section{References}

${ }^{1}$ Aster RH. Control of platelet production. In: Williams WJ, Beutler E, Erslev AJ, Rundles RW, eds. Hematology. New York: McGraw-Hill Book Company, 1972;1050-4.

${ }^{2}$ Levin J, Evatt BL. Humoral control of thrombopoiesis. Blood Cells 1979;5:105-21.
${ }^{3}$ Shreiner DP, Weinberg J, Enoch D. Plasma thrombopoietic activity in humans with normal and abnormal platelet counts. Blood 1980;56:183-8.

${ }^{4}$ Freedman MH, McDonald TP, Saunders EF. Differentiation of murine marrow megakaryocyte progenitors (CFUm): humoral control in vitro. Cell Tissue Kinet 1981;14:53-8.

5 Ebbe S, Stohlman F Jr, Donovan J, Overcash J. Megakaryocyte maturation rate in thrombocytopenic rats. Blood 1968;32: 787-95.

${ }^{6}$ Hoffman R, Mazur E, Bruno E, Floyd V. Assay of an activity in the serum of patients with disorders of thrombopoiesis that stimulates formation of megakaryocytic colonies. $N$ Engl J Med 1981;305:533-8.

${ }^{7}$ Meberg A, Jakobsen E, Halvorsen K. Humoral regulation of erythropoiesis and thrombopoiesis in appropriate and small for gestational age infants. Acta Paediatr Scand 1982;71:769-73.

${ }^{8}$ Bessler H, Sirota L, Weissman Z, Dulitzky F, Djaldetti M. Thrombopoietic activity in newborn infants. Biol Neonate 1986; 49:61-5.

9 Penington DG. Isotope bioassay for thrombopoietin. $\mathrm{Br} \mathrm{Med} \mathrm{J}$ 1970;i:606-8.

${ }^{10}$ McDonald TP. Bioassay for thrombopoietin utilizing mice in rebound thrombocytosis. Proc Soc Exp Biol Med 1973; 144:1006-12.

"Lundström U. Thrombocytosis in low birthweight infants. A physiological phenomenon in infancy. Arch Dis Child 1979;54:715-7.

12 Aballi AJ, Puapondh Y, Desposito F. Platelet counts in thriving premature infants. Pediatrics 1968;42:685-9.

13 Addiego JE Jr, Mentzer WC, Dallman PR. Thrombocytosis in infants and children. J Pediatr 1974;85:805-7.

14 Stockman JA III. Anemia of prematurity. Semin Hematol 1975;12:163-73.

Correspondence to Professor M Djaldetti, Department of Medicine "B", Hasharon Hospital, Petah-Tiqva 49372, Israel.

Received 18 March 1986. 